\title{
Meanings of Care Convoys: The Structure, Function, and Adequacy of Care Networks Among Frail, Community-Dwelling Older Adults
}

\author{
Deborah Lambotte' (D), An-Sofie Smetcoren', G. A. Rixt Zijlstra', \\ Jan De Lepeleire ${ }^{3}$, Liesbeth De Donder', Martinus J. M. Kardol', \\ and D-SCOPE Consortium*
}

\begin{abstract}
Researchers propose that the convoy of care model should be used to study care networks of frail, older individuals. Care convoys are defined as

the evolving collection of individuals who may or may not have close personal connections to the recipient or to one another but who provide care, including help with activities of daily living (ADLs) and instrumental activities of daily living (IADLs), socioemotional care, skilled health care, monitoring, and advocacy.
\end{abstract}

This study reports on community-dwelling older adults' experiences of their care convoy, how care convoys change over time, and perceived (positive) outcomes. A qualitative analysis among 65 semi-structured interviews with frail, community-dwelling older adults demonstrates a great variety in the composition of care convoys. Participants were often actively involved in their care convoy and valued the social/relational aspect of care. Care and support covered a wide range of activities, with some activities being provided by specific types of caregivers. Participants expressed the adequacy of their care convoy in terms of satisfaction and sufficiency. Noteworthy, participants who were satisfied with their care convoy did not necessarily receive sufficient help. Policies and practice should recognize the relational aspect of care, the complex interplay between all actors, and the dynamic character of care convoys.

\section{Keywords}

older adults; frailty; care convoys; Flanders; Brussels; qualitative research; thematic analysis

\section{Introduction}

There is an increasing focus in international literature on care and support of frail, community-dwelling older adults (José, Barros, Samitca, \& Teixeira, 2016). With increasing age, older adults can face physical, cognitive, psychological, social, and environmental problems (Dury et al., 2018; Grenier, 2007). When experiencing a need for care and support, informal caregivers (e.g., spouse, children, friends, neighbors) and formal caregivers (e.g., general practitioner, home nurse, cleaning services) have a crucial role for the continuance of "aging in place." This desire to stay at home for as long as possible is not only the preference of most frail, older adults (Smetcoren, 2015) but has also become a policy strategy in many Western governments to

* Details of the D-SCOPE Consortium is given in the Acknowledgments section cope with an aging society (Means, Richards, \& Smith, 2008). Due to austerity measures, formal care services are confronted with limited financial resources, and governments are encouraging informal caregivers to support frail, older adults at home (Broese van Groenou \& De Boer, 2016). At the same time, different demographic changes (e.g., declining family size) and societal developments (e.g., women's labor force participation) limit the availability of children as primary informal caregivers (Agree

\footnotetext{
'Vrije Universiteit Brussel, Brussels, Belgium

${ }^{2}$ Maastricht University, Maastricht, The Netherlands

${ }^{3}$ University of Leuven, Leuven, Belgium
}

\section{Corresponding Author:}

Deborah Lambotte, Department of Educational Sciences, Vrije Universiteit Brussel, Pleinlaan 2, 1050 Brussels, Belgium.

Email: deborah.lambotte@vub.be 
\& Glaser, 2009). Therefore, the proportion of frail, community-dwelling older adults receiving care and support from a diverse range of informal and formal caregivers is likely to increase in the coming years (Jacobs, Broese van Groenou, Aartsen, \& Deeg, 2018). The Flemish Senior Citizens policy plan 2015-2020 indicates that care is no longer solely the responsibility of professionals but a shared responsibility between care recipients, their social networks, and professionals (Flemish Government, 2015). In addition to the Flemish Senior Citizens policy plan 2015-2020, a Flemish informal care plan 2016-2020 has been developed, which promotes informal care and stimulates health care and social care professionals to take into account individuals' (social) environment (Vandeurzen, 2016).

A diverse collection of individuals who provide instrumental and emotional support to older adults because of their long-term health problems or functional limitations are labeled "care networks" (Keating, Otfinowski, Wenger, Fast, \& Derksen, 2003). To date, several studies explored care networks of community-dwelling older adults. Some of these studies suggest moving beyond a dyadic perspective for informal and formal care and the classical distinction between receiving (a) informal care only, (b) formal care only, or (c) both informal and formal care (Jacobs et al., 2018; Lambotte et al., 2018). For example, Lambotte et al. (2018) identified eight combinations of informal and formal care use in communitydwelling older adults. Other studies highlight the need to understand the linkages between informal and formal care (Ayalon \& Roziner, 2016; Jacobs, Van Tilburg, Groenewegen, \& Broese van Groenou, 2016). Existing theoretical models such as the substitution model (Greene, 1983), the task specificity model (Litwak, 1985), the hierarchical compensation theory (Cantor, 1991), and the complementary model (Chappell \& Blandford, 1991) are considered being too limited. In these conventional models, informal care and formal care are approached as separate systems rather than potentially overlapping arrangements and assume family care as preferred by care recipients (Ward-Griffin \& Marshall, 2003). These models also ignore care recipients as potentially active actors within their own care and support (Allen \& Ciambrone, 2003). Furthermore, they neither reflect the dynamic nature of care networks nor the increasing, complex needs of frail individuals (Kemp, Ball, \& Perkins, 2013). In reaction to these gaps, Kemp et al. (2013) have put forward the convoy of care model as a new, alternative approach for studying care networks.

The convoy of care model acknowledges the complexity and dynamicity of care networks. For their approach, Kemp et al. (2013) modified and expanded the convoy model of social relations (e.g., Kahn \& Antonucci, 1980) with insights from the life course theory (e.g., Elder,
1998), feminist gerontology (e.g., Ward-Griffin \& Marshall, 2003), social ecology (e.g., Moos, 1979), and symbolic interactionism (e.g., Blumer, 1969). Care convoys are defined as

the evolving collection of individuals who may or may not have close personal connections to the recipient or to one another, but who provide care, including help with activities of daily living (IADLs), socio-emotional care, skilled health care, monitoring and advocacy. (Kemp et al., 2013, p. 18)

A care convoy contains all of the people who provide support, including informal and formal caregivers. Care recipients are also directly involved in care relationships and are defined as active participants. Care convoy properties comprise structure (e.g., size, homogeneity, stability), function (e.g., support given, received, exchanged), and adequacy (e.g., satisfaction with support). Care convoys change and evolve over time through negotiations and are influenced by personal (e.g., gender, race, level of frailty) and societal (e.g., role expectations, norms) characteristics. Care convoys have outcomes for the care recipient (e.g., well-being), informal caregivers (e.g., level of care burden), and formal caregivers (e.g., job satisfaction).

To our knowledge, the convoy of care model has only been explored in the context of assisted living (Kemp et al., 2017, 2018, 2013). Within this context, care convoys often involve informal caregivers, assisted living staff, and multiple external care workers (Kemp et al., 2018, 2013). Residents are often care partners and participate in self-care and care management (Kemp et al., 2018). Several factors (e.g., social and material resources, caregivers' attitudes and beliefs) affect care convoys and either facilitate or constrain quality of life and quality of care (Kemp et al., 2018).

To date, there is little empirical evidence concerning care networks among community-dwelling older adults (Verver, Merten, Robben, \& Wagner, 2018). The study at hand addresses this research gap by exploring the meanings and experiences of frail, community-dwelling older adults concerning the structure, function, and adequacy of their care convoy, how their care convoy changes over time, and perceived (positive) outcomes of their care convoy.

\section{Method}

\section{Research Design}

The present study is a qualitative analysis of interviews with community-dwelling older adults at risk of frailty, collected in a larger study using a mixed methods design: the Detection, Support, and Care for Older people: Prevention and Empowerment (D-SCOPE) project (see 
Dury et al., 2018, for a detailed description). D-SCOPE aimed to explore (a) the lived experiences of communitydwelling older adults at risk of frailty about frailty, quality of life, care and support, mastery, and meaning in life; (b) balancing factors that might influence frailty and outcome variables such as informal and formal care; and (c) life changes and turning points and how these affect frailty, quality of life, care and support, meaning in life, and mastery. Between November 2015 and March 2016, 121 community-dwelling older adults at risk of frailty were interviewed in Flanders and Brussels. The results of the larger study can be found in Dury et al. (2018) and van der Vorst et al. (2017). The topic list for the interviews was developed together with the entire D-SCOPE research group, which consisted of 21 researchers specialized in gerontology, dementia, and/or frailty across several disciplines (e.g., neurology, general practice, psychology, educational sciences). The Human Sciences Ethical Commission of the Vrije Universiteit Brussel approved the research (Ref: ECHW_031).

\section{Procedures and Data Collection}

In the original study, community-dwelling older adults $(60+)$ at risk of frailty were recruited using a purposive sampling procedure. Five home care organizations recruited 64 participants from their client list and 57 participants were recruited via snowball sampling. Participants were included based on risk profiles for multidimensional frailty (Dury et al., 2017). Exclusion criteria were hospitalization and the person's incapacity to participate in the study (e.g., due to physical exhaustion, inability to provide adequate answers). Also, individuals who received a dementia diagnosis, as determined by a doctor (specialist or general practitioner), were excluded.

Eligible participants received written information about the study and signed an informed consent agreement before participation. They were informed about the voluntary nature of their involvement, their right to refuse to participate, and the confidentiality of their responses. Once the participants signed the informed consent form, trained researchers administered a quantitative questionnaire and a qualitative, in-depth interview in the language of the participant's choice. The quantitative questionnaire contained the Comprehensive Frailty Assessment Instrument-Plus (CFAI-Plus; De Roeck et al., 2018), the Montreal Cognitive Assessment Instrument (MoCA; Nasreddine et al., 2005), and numeric rating scales for quality of life, care and support, meaning in life, and mastery. The same researchers subsequently held semi-structured interviews with open-ended questions with the participants. The qualitative data collection comprised questions on experiences of frailty, frailty balance, care and support, positive outcomes, and life changes and
Table I. Characteristics of the Participants $(N=65)$.

\begin{tabular}{ll}
\hline Characteristics & $N$ \\
\hline Age & $\begin{array}{c}79.9 \text { years }(S D=8.7 \text {; range }=60-95 \\
\text { years })\end{array}$ \\
$\begin{array}{l}\text { Gender } \\
\text { Female }\end{array}$ & 42 \\
Male & 23 \\
Marital status & \\
Married & 14 \\
Widowed & 43 \\
Divorced & 6 \\
Never married & 2 \\
Migration background & \\
Yes & 12 \\
No & 53 \\
Medium-to-high frail & \\
Physical & 27 \\
Cognitive & 52 \\
Psychological & 20 \\
Social & 10 \\
Environmental & 14 \\
\hline
\end{tabular}

turning points. The interviews were conducted in Dutch or French by one of the researchers. For the participants with a migration background, an interpreter attended the interviews when necessary. The interviews took place in participants' home.

All interviews were digitally recorded and transcribed ad verbatim. All data were anonymized.

\section{Participants' Characteristics}

The present study $(N=65)$ used qualitative data from participants who had at least one informal caregiver (e.g., family member, friend, or neighbor) and who scored medium to high frail on at least one of the five domains of the CFAI-Plus (De Roeck et al., 2018). The CFAI-Plus, an extended version of the CFAI (De Witte et al., 2013), is a self-assessment instrument that measures five domains of frailty: physical, cognitive, psychological, social, and environmental frailty. Physical frailty comprises limitations in physical activities due to health problems. Psychological frailty includes mood disorders and emotional loneliness. Social frailty comprises social loneliness and lack of social support network. Environmental frailty includes housing conditions. Cognitive frailty assesses subjective cognitive complaints. Based on the results of the CFAI-Plus, older adults were grouped into (a) not-to-low frail, (b) low-tomedium frail, and (c) medium-to-high frail, for each domain of frailty (De Roeck et al., 2018). Table 1 presents the characteristics of the participants. 
Table 2. Main Labels of the Codebook Based on the Convoy of Care Model (Kemp, Ball, \& Perkins, 20I3).

\begin{tabular}{ll}
\hline Main Label & \multicolumn{1}{c}{ Subthemes } \\
\hline Structure: composition of care convoys & Types of informal caregivers \\
& Types of formal caregivers \\
& Self-care \\
Function: type of support given, received, and & Receiving care \\
exchanged in care convoys & Giving care \\
& Exchanging care \\
Adequacy: the quality of care convoys & Satisfaction \\
& Sufficiency \\
Changes within participants' care convoy & Type of change: immediate, gradual, temporary, lasting changes \\
& Changes in terms of satisfaction and sufficiency \\
(Positive) outcomes: results/consequences of & Aging well in place \\
care convoys & Feelings of inclusion \\
& Life satisfaction \\
& Quality of life \\
& Sense of mastery \\
\hline
\end{tabular}

\section{Data Analysis}

A qualitative analysis using thematic (content) techniques was conducted on the data and incorporated both deductive, concept-driven coding and inductive, data-driven coding (Fereday \& Muir-Cochrane, 2006). For the deductive coding, a codebook was developed from the research literature, which consisted of the main components of the convoy of care model (Kemp et al., 2013): (a) structure, (b) function, (c) adequacy, (d) life changes and turning points with regard to participants' care convoy, and (e) perceived (positive) outcomes of their care convoy. These were the main labels. Within this template, inductive coding took place for the creation of sublabels in the main labels, which allowed new themes to emerge from the interviews. Table 2 provides an overview of the main labels with the subthemes that emerged from the interviews.

Multiple researchers were involved in the coding process. Interviews were individually coded by the main researcher. Consensus on the codebook was achieved through discussion and involved two additional experts in care and support. The final codebook and findings were discussed with all researchers.

The interviews were coded using the software program MAXQDA. This program facilitates thematic content analyses (Oliveira, Bitencourt, Teixeira, \& Santos, 2013).

\section{Results}

\section{The Structure of Care Convoys}

The interviews revealed a great variety in the structure of participants' care convoy. Regarding informal care, participants often labeled their spouse and children as their primary informal caregivers. In some cases, also friends and neighbors were actively mentioned, whether or not family caregivers were available. One participant explained that a friend took care of her:

Especially for the administration. She takes good care of me. We also call each other, and she always brings me good food. She has my credit card. I trust her completely. (Woman, 81 years, widowed)

Regarding formal care, participants received care and support from a wide range of professionals and different types of organizations: the general practitioner, physiotherapist, home nurse, housecleaning, and so on. Besides these rather "typical" formal care services, participants mentioned receiving assistance from social service centers, "meals on wheels," specialized transport, and so on and declared to use assistive tools such as a personal alarm system, walking stick, rollator, or stairlift. Due to reduced mobility, participants expressed their incapacity to leave their home independently. Therefore, several local merchants (e.g., bakery, pharmacy, hairdresser) delivered their products and services at home. One participant explained,

The pharmacist delivers my medication in the morning. He puts six pills in this box [points to his pill box]. He comes every day. And he also contacts the doctor for the medication. (Man, 81 years, widowed)

Some care convoys were small containing one or two caregivers, and other care convoys comprised multiple caregivers who shared responsibilities. The latter participants often received more intensive care and support on a more regular basis. 


\section{The Function of Care Convoys}

Throughout the interviews, participants indicated they took care of themselves, cared for others, received care, and exchanged care.

Self-care. Participants emphasized the importance of caring for themselves as much as possible to reduce their dependency on others. In general, participants tried to maintain and increase their independency in two ways. First, participants adapted and found new ways to manage their daily tasks, so they would need less or no assistance. An 81-year-old married man stated,

I still do the grocery shopping by myself. I cannot lift 6 bottles of 1.5 liter water in one time. Or 6 cartons of milk. So, I have a pocket knife in my car. I take it with me, I cut the package open and I put one bottle at a time in the shopping cart and one bottle at a time in the car. And I do this at home too.

Second, participants demonstrated active involvement in both informal and formal care relationships (e.g., by telling their (in)formal caregivers what to do and asking questions). Some participants participated in the care activity itself. Although this was principally the case with their informal caregivers, sometimes participants also contributed that way in formal care settings. A 72-yearold widow said,

And when the cleaning lady comes, I say "I will take care of this," but I cannot do anything in heights and she knows so she responds, "normally I'm paid to do that." But actually, I want to do it to prove to myself that I am still worth something and that I am not a lazy person.

In some cases, participants did not receive the opportunity to be involved in the care setting. One participant explained how her general practitioner discussed the care situation with her daughter without involving her:

Sometimes he [general practitioner] calls my daughter [and says] "Madam, I am here with your mother. There is not much progress with that medication. I suggest doing a scan." And subsequently I receive a date. (Woman, 80 years, widowed)

One participant deliberately chose to receive formal care which actually was not needed (anymore). She was able to take care of herself but decided to keep using formal care services as a reassurance, a form of social control:

Someone already came to prepare my meal. The nurse will come to take my blood pressure, prepare my medication and check if everything is alright. Nobody will come until the evening, to put me in bed at ten o'clock. I might be able to do all this on my own, but I do not want to do it because of what happened in the past. My disease can reoccur at any time and I could lie here for days if nobody would come. (Woman, 85 years, widowed)

Receiving care. Participants required care and support within various activities, including personal care (e.g., preparing medication, bathing, dressing), home care (e.g., preparing meals, administration, grocery shopping, housecleaning), transportation, and socioemotional support. According to the participants, personal care and housecleaning were tasks mainly delivered by formal caregivers, and informal caregivers supported them principally in other home activities such as administration, transportation, and socioemotional support. Informal caregivers also helped and supported them in additional tasks such as carrying out house modifications. A 91-yearold widow explained,

My daughter-in-law takes care of everything. For example, she closed the gas fire. It does not work anymore, so I cannot accidently activate it. She bought me a little oven and also an indoor dustbin. I am comfortable now. Absolutely, I feel like a queen.

Family members cared more extensively for the participants, whereas friends and neighbors provided less intensive care and support, as they especially helped with "little" things. In some cases, this distinction was present for the same activity. One participant explained for grocery shopping,

My daughter calls me the day before she comes to visit and asks me what groceries I need. She brings me what I need for a little while. And my neighbor buys bread, little things like this. (Woman, 80 years, divorced)

There are also exceptions in which neighbors take on a more extensive role. One of the participants indicated to rely on his neighbor for almost everything:

Cooking, housecleaning, shopping, my payments, . . . I do not think she can do more because there is not much else she can do. (Man, 82 years, divorced)

In general, participants valued the social contacts within their informal and formal care relationships and attributed positive outcomes to these social relations. One participant indicated she felt less lonely and depressed:

I suffered from a depression one year ago. So, I went to the hospital and upon my return I started home care. Miraculously, after 6 months I managed to overcome my depression. It is probably due to the home care team because 
seeing and speaking 3 times a day to someone, the human contact, it must have been my cure I think. (Woman, 91 years, widowed)

With regard to informal care, participants explicitly appreciated the moments with their informal caregivers that went beyond the care and support tasks (e.g., going to the restaurant, go shopping together). With regard to formal care, participants enjoyed sharing a cup of coffee with their formal caregivers, which gave them a moment to talk about personal stories. In some cases, participants developed meaningful relationships with their formal caregivers. An 80-year-old widow explained she went on an excursion with her cleaning lady:

She called me last year, "We are going to visit the capital by train. Do you want to join?" Yes! And we went to Brussels by train.

Some types of formal care also caused informal social contacts to increase. One participant said about going to the day care center:

Yes, I like that. I like to be among people. And we chat, play cards. You see people come and go. You have lunch together. (Woman, 81 years, widowed)

In some cases, despite the presence of informal caregivers, participants valued the relationship with formal caregivers more.

Giving care. Participants in some cases cared for others while receiving care and support themselves. Participants indicated to carry a great burden when taking care of loved ones with a high demand for care (e.g., disabled child or spouse). They felt neither understood nor assisted by their social environment including their informal caregivers and expressed worries and feelings of exclusion. One participant took care of her son who had a mental disorder and explained she lacked support from her other children:

Apparently, it is too heavy for the other children. And they leave me with it. You know, they have their own household and busy schedules. (Woman, 84 years, widowed)

Some of the participants appealed to formal care and experienced this as a relief because they could not provide the necessary care and support anymore. One participant who was an informal caregiver for his wife explained,

I receive home care. I do the grocery shopping, but I cannot cook anymore. She [formal caregiver] prepares the vegetables and puts the food in boxes that I can warm up in the microwave. That is a relief. But I still have a lot of worries. (Man, 88 years, married)

Some participants helped others with less intensive care tasks, for example, by helping neighbors or taking care of (great-)grandchildren. Those care tasks were considered as meaningful and useful. An 87-year-old widow indicated,

As the daughter lives too far away, I suggested her to do it. I just have to cross the street and give her [neighbor] the eye drops.

Exchanging care. Participants demonstrated reciprocity with their caregivers in several ways. First, participants provided gifts or financial support. Second, reciprocity arose in the form of caring relationships. This was often the case for spouses who took care of each other. But participants also expressed a sense of reciprocity regarding assistance from other types of caregivers. A 76-year-old married man explained,

If they [neighbors] need me or if I can do anything for them, I will do it. And it also works the other way around. If I ask something, I know I can count on them.

Finally, participants expressed reciprocity by showing gratitude and respect to their caregivers.

\section{The Adequacy of Care Convoys}

Participants expressed the adequacy of their care convoy in two ways: the extent to which they were satisfied of their care convoy and the extent to which their care convoy was sufficient.

Satisfaction. Participants mentioned several aspects which contributed to their care convoy satisfaction. First, participants appreciated being treated with respect and commitment. One participant explained how her formal caregiver did not respect her cultural traditions:

With the Turkish people you need to take off your shoes when you enter. And she likes it very much when people do this. She even offers little slippers instead. The last time a Moroccan nurse arrived, Mrs. asked "Can you take off your shoes?" And the nurse refused to do it. (Translator for woman, 60 years, married)

Another participant stated how her informal caregiver emphasized her limitations and how this made her feel bad:

I used my portable toilet and my sister said, "I am first going to carry the toilet outside because it stinks in here." I cannot 
do anything about that, I cannot carry it outside by myself. "You have to open the windows," she said. To which I replied, "Open the windows? Then they [formal caregivers] have to wait and close the windows again, because I cannot." "Yes, that is true," she said. And you know what I also responded to her? "You may still be happy that I do not wet my pants." She said, "You do not have to take it so seriously." But it was said, and I really felt hurt. (Woman, 87 years, widowed)

Second, participants valued the possibility to appeal on the availability of their caregivers if something would happen. This was mainly the case for informal caregivers due to their proximity. Participants explained how living with or close to their informal caregivers made them feel safe and reassured:

You are more relaxed. If something happens, you know where to go, you know who to call, who can help you. That is what matters to me. (Man, 76 years, married)

Participants experienced this reassurance also in "alternative" formal home care services such as Care 24 (i.e., home care nursing services also during the night) and FocusPlus (i.e., alternative housing arrangement with personal alarm system directly connected to professionals working in the building). An 82-year-old divorced man indicated that Care 24 reassured his informal caregiver as well:

I am lucky that those nurses come day and night. They also come twice during the night. So, in fact that is a reassurance. And a reassurance for her [i.e. informal caregiver] too.

However, living close by was not always a guarantee for instant help:

My daughter lives nearby. I cannot complaint about her. But sometimes I assume that she would help her father a bit more. I do not hear of her. It is not always like this, but for example yesterday and the day before I did not see her. (Man, 90 years, widowed)

Finally, participants were not satisfied about some aspects related to formal care specifically. The first aspect concerned the time at which formal caregivers provided care. One participant explained,

A nurse comes twice a week. In the beginning she came at 10 or 11 o'clock. That was not bearable because it forced me to stay in my pajamas for so long. And now she comes around 9 o'clock. This morning she was here at 8 o'clock. (Woman, 72 years, widowed)

Participants were not always able to trust formal caregivers because they switched. Related to this aspect, some participants indicated that you needed to be lucky because not all formal caregivers did their job well.

Sufficiency. Participants experienced care shortages in both informal and formal care arrangements. Some participants stated, while being satisfied with their care and support, that they did not receive enough assistance.

Within informal care settings, participants explained how their informal caregivers were not always able to give sufficient care and support due to a lack of time. Informal caregivers often had a job, their own household, and so on. In some cases, informal caregivers lived far from the participants. An 80-year-old widow indicated when needing help for transportation:

If she [daughter] is on duty, she must stay at the hospital. And then I do not know whether my other daughter would drive from the coast for me. So, what should I do? I call a taxi.

Also, participants experienced boundaries when asking for informal help. Participants noticed their informal caregivers were burdened and exhausted. They felt guilty about being dependent on their informal caregivers. One participant explained,

If I am not well anymore, I will ask to leave. I wish to stay at home for as long as possible. But if I notice that this care situation becomes too difficult for her [daughter], I do not want to do that to her either. I feel already bad for her. (Woman, 94 years, widowed)

Informal caregivers were also sometimes frail and in need of assistance themselves.

Within formal care settings, participants explained how the necessary administration and long waiting lists discouraged them to arrange care. Subsequently some participants received insufficient formal care due to their low income and the high price of some care possibilities and assistive means.

\section{Changes in Care Convoys}

Several events occurred in participants' lives which brought changes in their care convoy. Some events caused almost immediate changes (e.g., not allowed to drive anymore), whereas others generated gradual changes (e.g., physical deterioration). Some events also caused temporary changes (e.g., surgery), whereas other events created lasting changes (e.g., illness).

These changes had consequences for the structure, function, and adequacy of participants' care convoy. Participants explained how their care convoy grew as 
existing caregivers provided more intensive care and/or new caregivers appeared. An 81-year-old widow explained how her physical deterioration caused more intensive care:

The doctor needs to come more often. I take more expensive medication. That was not the case before. Now I also have to pay a cleaning lady.

Sometimes care convoys became smaller. One participant indicated that her friends do not help her anymore due to personal circumstances:

I used to have friends. They helped me with the grocery shopping. One does not come anymore because of the travel distance. She is suffering from Multi Sclerosis. And she looks after her grandchildren. And another friend also has a grandchild now and she looks after him every day. (Woman, 69 years, divorced)

Certain care activities were taken over by others. One participant explained her son moved away, and her other son took over the assistance; however, she is not satisfied with this change at all:

I regret that he [son] now lives at the coast. The other one is not that affectionate. Back then, he came to visit me once in a while. I miss that now. (Woman, 85 years, widowed)

\section{Positive Outcomes of Care Convoys}

Participants recognized the positive outcomes of their care convoy for themselves. They described the need of their care convoy to age well in place. With the help of others, they felt in some way autonomous and more in control of their daily lives. Care convoys also contributed to the quality of life and life satisfaction of the participants. The following quote expresses how a home care organization brought happiness:

I really enjoy the organization. I do not say it for the customers or to make you feel good. No, it is superb, it is a great organization. (Woman, 91 years, widowed)

Informal and formal caregivers also contributed to the inclusion of the participants by stimulating them to go outside and to participate in activities (e.g., the general practitioner advised one of the participants to go to the local service center, several formal care services organized activities outside the home and provided special transport). One participant went to the library to join a reading group due to her daughter:
I go to the library with my walker. I am in a reading group, which is a group where we have to read books. My daughter works at the library and she absolutely wanted me to participate in this group. (Woman, 86 years, widowed)

\section{Discussion}

The interviews revealed a great diversity in the structure of care convoys among frail, community-dwelling older adults who indicated to receive assistance from both various informal caregivers (e.g., spouse, children, siblings, friends, neighbors) and various formal caregivers (e.g., general practitioner, home nurse, housecleaner). Besides the above-mentioned types of caregivers, older adults also considered other services (e.g., social service centers, assistive means) and local merchants (e.g., pharmacist, hairdresser) as types of professional support. Most informal care was provided by the spouse or children. However, participants also indicated friends and neighbors as informal caregivers. Authors highlight the evolving patterns of care and growing importance of nonkin care due to the changing structure, nature, and roles within the family and societal trends like women's labor force participation (Agree \& Glaser, 2009). Similar to Kemp et al. (2018), some care convoys contained a primary informal caregiver who provided most of the informal care, whereas other care convoys contained several caregivers and shared responsibilities. Informal and formal care frequently co-occurred in frail, older adults (Lambotte et al., 2018).

Diversity is present not only in the structure of care convoys but also in the function of care convoys among frail, community-dwelling older adults. Namely, the participants of the current study explained caring for themselves, caring for others, receiving care, and exchanging care with their (in)formal caregivers. Furthermore, participants' understanding of care and support covered a wide range of activities (e.g., personal care, transportation, social and emotional support). Noteworthy is the importance of social contacts within informal and formal care relationships. Several studies highlight the significance of interpersonal relations between care provider and care receiver, and the "social" dimension of care (Cooney, Dowling, Gannon, Dempsey, \& Murphy, 2014; Walsh \& Shutes, 2013). Caregiving is not only instrumental but also involves emotional and personal aspects. Participants of the current study valued the social interactions that resulted from the care and support activities and showed personal attachment toward the individuals who cared for them. Some participants indicated not having the possibility to develop a relational continuity (e.g., due to lack of time of caregivers, formal caregivers' shifts) 
and mentioned this as a reason why they were not completely satisfied with their care. This is in line with previous research that showed that care provided by the same caregiver over a considerable time is important to generate safety, security, and trust in older adults (José et al., 2016). The social dimension of care also reflects the complexity of care convoys of frail, older adults as participants experienced different kinds of relationships depending on the specific caregiver. An example of this complexity is participants' desire for social interactions with their formal caregivers such as the housecleaner, and this aspect has in many cases more value than the assistance itself. Furthermore, informal caregivers are not necessarily the closest one to the care recipient. In some cases, participants felt more affection for their formal caregivers.

Another important finding within care convoys' function concerns the active involvement of frail, older adults. This is in contrast with the unequal power relations which lie in much of today's discourse on care and support (Eliassen, 2016). The focus on pathologies and deficits reinforces stereotypes of frailty and dependency and frames older adults as a vulnerable group requiring special assistance. Implicit stereotyping often influences interactions of formal caregivers with older adults and their social environment and affects older adults' perceptions and health outcomes. In this study, participants expressed active involvement in several ways. In accordance with Kemp et al. (2018), participants indicated to be actively involved in their care convoy by their capacity for self-care. A central element of self-care is decision making (Lommi, Matarese, Alvaro, Piredda, \& De Marinis, 2015). Participants in this study made decisions about the self-care activities they perform and the activities they delegate to others. Similar to the study of Gregory, Mackintosh, Kumar, and Grech (2017), the care setting was characterized by negotiation between the care recipient, and informal and/or formal caregivers. Participants also showed active involvement in reciprocal relationships or relationships in which older adults were able to exchange with their caregivers. Similar to existing studies (e.g., Åberg, Sidenvall, Hepworth, Reilly, \& Lithell, 2004; Erlingsson, Magnusson, \& Hanson, 2012), this study exposes different dimensions of reciprocity. Reciprocity concerned not only actual exchanges between caregiver and care recipient. The idea that one would give assistance if ever needed was seen as a form of reciprocity by the participants. Older participants also expressed their gratitude and appreciation toward the individuals who cared for them. Lewinter (2003) defines this as symbolic reciprocity and facilitates the provision of care. Finally, some participants - while receiving care-also took care of others and thus were informal caregivers themselves. Gibson (1985) acknowledges reciprocity as a crucial factor for independence in later life. Being able to reciprocate strengthens an individual's sense of independence while facilitating keeping some sense of control over the situation in which exchanges occur.

Those results demonstrate that complexity does not only arise in care convoys but are also part of human beings as older adults can be both frail and resourceful at the same time. Frailty can be defined as a dynamic process by which individuals react to environmental factors (Nicholson, Meyer, Flatley, \& Holman, 2013). Based on ideas of Brocklehurst (1973), Rockwood, Fox, Stolee, Robertson, and Beattie (1994) conceptualized a dynamic model of frailty which recognizes the complex balance of assets and deficits that maintain or threaten individuals' independence. One side of the balance are assets (e.g., health, functional capacity, social and financial resources), which help individuals to maintain their independence in the community. The other side of the balance are deficits (e.g., illness, chronic disease, disability), which threaten independence. The model is dynamic as it can change in status by adjusting the weights of the various assets and deficits. In line with this perspective, several authors suggest approaching old age from an interdependency perspective instead of a dependency perspective (Boudiny, 2013). Fine and Glendinning (2005) recommend a more diverse conceptualization to understand the interrelational nature of care and support instead of the simple dichotomy of "caregiver" versus "care receiver." They define interdependence as "the result of reciprocity between partners, exchanges between dependent actors over time, and the networking of these relations of dependence" (Fine \& Glendinning, 2005, p. 61). Interpersonal interactions are socially and culturally constructed and confirm current beliefs and attitudes of ourselves and of others (Coudin \& Alexopoulos, 2010). Adopting a culturally competent approach would offer the possibility for health care professionals to include social and cultural beliefs in the provision of care and support (Garneau, Bourbonnais, \& Pepin, 2018).

Care convoys showed functional differences between informal and formal care. Participants explained how personal care and housecleaning were care tasks mainly delivered by formal caregivers, whereas informal caregivers supported the participants principally in other home care activities (e.g., administration), transportation, and socioemotional support. These results show that both informal care and formal care have their own dynamics, and that some care tasks are more likely to be provided by specific caregivers. According to Hoefman, Meulenkamp, and De Jong (2017), people believe that governments are more responsible for personal and nursing care activities such as bathing or dressing and wound care, whereas informal caregivers hold more responsibility for social needs and support activities such as support 
with administration. In the current study, there were also functional differences within informal care. Participants often explained how family members cared more extensively while nonkin caregivers provided less intensive care and support, sometimes for the same care activity. Differences in types of assistance between friends/neighbors and family members exist as friends and neighbors limit their assistance to practical tasks such as assistance with transport and socioemotional support (RIS MRC CFAS et al., 1998). An explanation could be in the nature of the relationship, resulting in differences in motivation to provide assistance. The motivation for family caring is often based on obligation and duty (Finch \& Mason, 1993). This does not apply to the same extent with nonrelatives (Atkin, 1992).

In accordance with Morrow-Howell, Proctor, and Dore (1998), frail, older adults in the current study expressed the adequacy of their care convoys in terms of satisfaction and sufficiency. Satisfaction refers to the qualitative dimension of adequacy, and sufficiency refers to the quantitative dimension. Both dimensions are not necessarily related to each other as the participants of this study who were satisfied with the care received did not necessarily receive sufficient help, or vice versa. An important aspect related to frail, older adults' satisfaction of their care convoys was being treated with respect and commitment. This is in line with José et al. (2016), suggesting that having respectful and attentive caregivers is an aspect of good care. Those caregivers respect the preferences and wishes of older adults, treat them as capable persons, and support and simulate them to make their own choices. With regard to both the quantitative and qualitative component of adequacy, proximity and time played an important role. Regarding proximity, the current study showed similar findings to a study by Broese van Groenou and De Boer (2016) as participants explained that living near their informal caregivers was an advantage as it made them feel more secure. In line with Mello et al. (2017), participants in the current study indicated informal caregivers' lack of time because they often had additional roles to fulfill and were in some cases overburdened. Older adults tried to cope with this by asking other caregivers for help.

In line with a qualitative study from Kruijswijk, Da Roit, and Hoogenboom (2015), this study demonstrates that care convoys are dynamic and change over time. This study provides evidence that changes are inherent not only to the structure of care convoys but also to their function and adequacy. Participants indicated various changes which made their care convoy's structure, function, and adequacy to change (temporarily or permanently). Some events were associated with the well-being and health of participants; other events were inherent to informal caregivers' life.
Finally, care convoys had several (positive) outcomes for frail, community-dwelling older adults. Like in other studies focusing on care and support (e.g., Lloyd, Kendall, Starr, \& Murray, 2016; Stones \& Gullifer, 2016), care convoys contributed to the participants' life satisfaction, quality of life, and aging well in place. In addition, the participants in this study also described the importance of their care convoy for inclusion and participation in the community.

\section{Strengths and Limitations}

Several limitations need to be acknowledged. First, there may have been inconsistencies between the interviews because several authors conducted them. To extend the reliability of the interviews, the interviewers received training before conducting the interviews (Boeije, 2010). This training included the following: (a) explanation and discussion of the study protocol, (b) explanation and exercises on administering the MoCA (led by a psychologist), (c) debriefing regarding the instructions for the translated questionnaires, and (d) practice conducting the interviews with simulated patients while being recorded. Several scenarios were also developed to address potential difficulties, and all interviewers received a list of definitions explaining the terms used in the questionnaire, which could be used if necessary during the interviews. Second, this study started with deductive analysis as the structure of the analysis was operationalized on the basis of previous knowledge, namely key elements from the convoy of care model (Kemp et al., 2013). This could be seen as a limitation because one might want to fit the data into preexisting codes, instead of looking at the core of the data and organizing themes accordingly. However, this type of analysis is useful to test a previous theory in a different situation (Elo \& Kyngäs, 2008; Hsieh \& Shannon, 2005). This is the case as the convoy of care model has only been explored in older adults living in assisted living (Kemp et al., 2013). Furthermore, by adding inductive coding within the framework, we let subthemes emerge from participants' experiences. Through this process, it was possible to identify how themes were generated from the data to uncover meanings in relation to frail, community-dwelling older adults' care convoy (Fereday \& Muir-Cochrane, 2006).

Despite these limitations, this study has a number of strengths. To ensure the trustworthiness of the findings, the coauthors of this study engaged with other researchers to reduce research bias by presenting and discussing preliminary results of the study (Noble \& Smith, 2015). To enhance the credibility of the findings, the themes were subject of discussion with the team members, and several extracts from various interviews are provided to illustrate the findings (Noble \& Smith, 2015). 


\section{Recommendations for Future Research, Policy, and Practice}

With regard to future research, (in)formal caregivers should be involved in the exploration of care convoys as well. Namely, studies involving caregivers' voices indicate the existence of discrepancies between the perceptions of the various actors (Brimblecombe, Pickard, King, \& Knapp, 2017; Turcotte et al., 2015).

Different recommendations with regard to policy and practice need to be made. First, this study supports Wiles's (2011) critiques of ageist views, which assume older care recipients to be unproductive and dependent on others. In line with several scholars (e.g., Tronto, 1993), this study acknowledges the need for reconceptualizing care as relationships of interdependence between complex networks of actors in various contexts. As Fine and Glendinning (2005) point out, both care recipients and care providers are involved in the coproduction of care, wherein different types of care and support are exchanged. The multiple voices within care relationships should be acknowledged and strategies need to be developed in which informal caregivers, formal caregivers, and frail individuals can be meaningfully involved within different complex situations (Witham, Haigh, Mitchell, \& Beddow, 2018).

Second, this study points toward a strengths-based approach to frailty. In addition to the registration of deficits and dependency, one should also register older adults' assets or strengths (like the presence of care convoys) in managing their everyday life (Nicholson, Gordon, \& Tinker, 2017). This approach is in line with the needs and wishes of community-dwelling older adults. They prefer a focus on autonomy and well-being, rather than on deficits (Lette, Baan, van den Berg, \& de Bruin, 2015). Furthermore, merely focusing on things individuals can no longer do can be stigmatizing. When older adults are labeled as frail, this often makes them behave accordingly (Warmoth et al., 2016). Initiatives such as "reablement" focus on competences and opportunities to perform certain activities again (Aalbers et al., 2016). Also, programs such as "Stay Active at Home" emphasize competences and resources by focusing on "doing with" rather than "doing for" (Metzelthin et al., 2017). Those initiatives strengthen the quality of community health and social care and permits older adults to age well in place for as long as possible.

Finally, the social and relational aspect of care should receive more value in the provision of care and support. The way how most formal home care is delivered hampers relational continuity (e.g., lack of time, switching between caregivers). Services should aim at formal caregivers to maintain and improve relational continuity with frail, older adults. For example, addressing organizational factors (e.g., fostering consistency of personnel, reducing the number of visits per professional) and facilitating the development of an ongoing relationship (e.g., training) would improve quality of care and support (Waibel, Vargas, Coderch, \& Vàzquez, 2018). Also, informal caregivers could be supported in light of relational continuity. To help informal caregivers to fulfill the roles they undertake, policies on informal care should focus not only on informal caregivers' well-being but also on social inclusion (e.g., facilitating flexible working hours, giving pension credits for care time, providing training) (Eurocarers, 2019).

\section{Conclusion}

In the context of community care, frail, community-dwelling older adults are likely to receive care and support from a diverse range of informal and formal caregivers. This study explores the meaning and experiences of frail, older adults' care convoy (i.e., structure, function, and adequacy of care convoys; how care convoys change over time; and perceived (positive) outcomes for themselves). The interviews revealed a great diversity in the structure of care convoys as participants indicated to receive assistance from both various informal and formal caregivers. Diversity is also present in the function of care convoys as participants explained caring for themselves, caring for others, receiving care, and exchanging care with their (in) formal caregivers. Participants exerted active involvement within their care convoy and valued social and relational aspect of care. Participants' understanding of care and support covered a wide range of activities, with some activities being more likely to be provided by specific types of caregivers. Participants expressed the adequacy of their care convoys in terms of satisfaction and sufficiency. Noteworthy, one does not necessarily lead to the other as participants who were satisfied with the care received did not necessarily receive sufficient help, or vice versa. Care convoys are dynamic and change over time. These changes are not only inherent to the structure of care convoys but also to their function and adequacy. Participants in this study described their care convoy's importance for sense of mastery, quality of life, life satisfaction, inclusion, and aging well in place. (Health) care practice and policies should acknowledge the relational and social aspect of care; the complex interplay between care recipients, and informal and formal caregivers; and the dynamic character of care convoys of frail, community-dwelling older adults. Adopting a strengths-based approach to frailty will give the opportunity to explore older adults' assets or strengths within care convoys, which will improve the quality of community health and social care and will support older adults to age well in place for as long as possible. 


\section{Acknowledgments}

The Detection, Support, and Care for Older people: Prevention and Empowerment (D-SCOPE) is an international research consortium and is composed of researchers from Vrije Universiteit Brussel, Belgium (Dr. A-.S. Smetcoren, Dr. S. Dury, Prof. Dr. L. De Donder, Prof. Dr. E. Dierckx, D. Lambotte, B. Fret, D. Duppen, Prof. Dr. M. Kardol, Prof. Dr. D. Verté); College University Ghent, Belgium (L. J. Hoeyberghs, Prof. Dr. N. De Witte); Universiteit Antwerpen, Belgium (E. E. De Roeck, Prof. Dr. S. Engelborghs, Prof. Dr. P. P. De Deyn); Katholieke Universiteit Leuven, Belgium (M. Van der Elst, Prof. Dr. J. De Lepeleire, Prof. Dr. B. Schoenmakers); and Maastricht University, The Netherlands (A. van der Vorst, Dr. G.A.R. Zijlstra, Prof. Dr. G .I. J. M. Kempen, Prof. Dr. J. M. G. A. Schols). The authors warmly thank the older adults who participated in the study.

\section{Declaration of Conflicting Interests}

The authors declared no potential conflicts of interest with respect to the research, authorship, and/or publication of this article.

\section{Funding}

The authors disclosed receipt of the following financial support for the research, authorship, and/or publication of this article: This research was supported by a grant from the Flemish government agency for Innovation by Science and Technology (grant number IWT-140027 SBO].

\section{ORCID iD}

Deborah Lambotte iD https://orcid.org/0000-0002-0670-3351

\section{References}

Aalbers, T., Qin, L., Baars, M. A. E., de Lange, A., Kessels, R. P. C., \& Rikkert, M. G. M. O. (2016). Changing behavioral lifestyle risk factors related to cognitive decline in later life using a self-motivated eHealth intervention in Dutch adults. Journal of Medical Internet Research, 18(6), e171. doi:10.2196/jmir.5269

Åberg, A. C., Sidenvall, B., Hepworth, M., O’Reilly, K., \& Lithell, H. (2004). Continuity of the self in later life: Perceptions of Informal caregivers. Qualitative Health Research, 14, 792-815. doi:10.1177/1049732304265854

Agree, E. M., \& Glaser, K. (2009). Demography of informal caregiving. In P. Uhlenberg (Ed.), International handbook of population aging (pp. 647-668). New York: Springer.

Allen, S. M., \& Ciambrone, D. (2003). Community care for people with disability: Blurring boundaries between formal and informal caregivers. Qualitative Health Research, 13, 207-226. doi:10.1177/1049732302239599

Atkin, K. (1992). Similarities and differences between informal carers. In J. Twigg (Ed.), Carers: Research and practice (pp. 30-58). London: Her Majesty's Stationery Office.

Ayalon, L., \& Roziner, I. (2016). Satisfaction with the relationship from the perspectives of family caregivers, older adults and their home care workers. Aging \& Mental Health, 20(1), 56-64. doi:10.1080/13607863.2015.1020412

Blumer, H. (1969). Symbolic interaction: Perspective and method. Englewood Cliffs, NJ: Prentice Hall.

Boeije, H. (2010). Analysis in qualitative research. London: SAGE.

Boudiny, K. (2013). "Active ageing": From empty rhetoric to effective policy tool. Ageing \& Society, 33, 1077-1098. doi:10.1017/S0144686X1200030X

Brimblecombe, N., Pickard, L., King, D., \& Knapp, M. (2017). Perceptions of unmet needs for community social care services in England. A comparison of working carers and the people they care for. Health and Social Care in the Community, 25, 435-446. doi:10.1111/hsc.12323

Brocklehurst, J. C. (1973). Textbook of geriatric medicine and gerontology. London: Churchill.

Broese van Groenou, M. I., \& De Boer, A. (2016). Providing informal care in a changing society. European Journal of Ageing, 13, 271-279. doi:10.1007/s10433-016-0370-7

Cantor, M. (1991). Family and community: Changing roles in an aging society. The Gerontologist, 31, 337-346. doi:10.1093/geront/31.3.337

Chappell, N., \& Blandford, A. (1991). Informal and formal care: Exploring the complementarity. Ageing \& Society, 11, 299-317. doi:10.1017/S0144686X00004189

Cooney, A., Dowling, M., Gannon, M. E., Dempsey, L., \& Murphy, K. (2014). Exploration of the meaning of connectedness for older people in long-term care in context of their quality of life: A review and commentary. International Journal of Older People Nursing, 9, 192-199. doi:10.1111/ opn.12017

Coudin, G., \& Alexopoulos, T. (2010). "Help me! I'm old!" How negative aging stereotypes create dependency among older adults. Aging \& Mental Health, 14, 516-523. doi:10.1080/13607861003713182

De Roeck, E. E., Dury, S., De Witte, N., De Donder, L., Bjerke, M., De Deyn, P. P., . . . Dierckx, E. (2018). CFAI-plus: Adding cognitive frailty as a new domain to the comprehensive frailty assessment instrument. International Journal of Geriatric Psychiatry, 33, 941-947. doi:10.1002/gps.4875

De Witte, N., Gobbens, R., De Donder, L., Dury, S., Buffel, T., Schols, J., \& Verté, D. (2013). The comprehensive frailty assessment instrument: Development, validity and reliability. Geriatric Nursing, 34, 274-281. doi:10.1016/j.gerinurse.2013.03.002

Dury, S., De Roeck, E., Duppen, D., Fret, B., Hoeyberghs, L., Lambotte, D., . . . Dierckx, E. (2017). Identifying frailty risk profiles of home-dwelling older people: focus on sociodemographic and socioeconomic characteristics. Aging \& Mental Health, 21, 1031-1039. doi:10.1080/136 07863.2016.1193120

Dury, S., Dierckx, E., van der Vorst, A., Van der Elst, M., Fret, B., Duppen, D., . . . De Donder, L. (2018). Detecting frail, older adults and identifying their strengths: Results of a mixed-methods study. BMC Public Health, 18, Article 191. doi:10.1186/s12889-018-5088-3

Elder, G. H. (1998). The life course and human development. In R. M. Lerner (Ed.), Handbook of child psychology: 
Theoretical models of human development (pp. 939-991). New York: John Wiley.

Eliassen, A. H. (2016). Power relations and health care communication in older adulthood: Educating recipients and providers. The Gerontologist, 56, 990-996. doi:10.1093/ geront/gnv095

Elo, S., \& Kyngäs, H. (2008). The qualitative content analysis process. Journal of Advanced Nursing, 62, 107-115. doi:10.1111/j.1365-2648.2007.04569.x

Erlingsson, C. L., Magnusson, L., \& Hanson, E. (2012). Family caregivers' health in connection with providing care. Qualitative Health Research, 22, 640-655. doi:10.1177/1049732311431247

Eurocarers. (2019). Informal care, poverty and social exclusion. Supporting informal carers must be a key component of policies aimed at strenghtening social cohesion, for the benefit of the whole society. Retrieved from https://eurocarers.org/publications/informal-care-poverty-and-socialexclusion/

Fereday, J., \& Muir-Cochrane, E. (2006). Demonstrating rigor using thematic analysis: A hybrid approach of inductive and deductive coding and theme development. International Journal of Qualitative Methods, 5, 80-92. doi:10.1177/160940690600500107

Finch, J., \& Mason, J. (1993). Negotiating family responsibilities. London: Tavistock/Routledge.

Fine, M., \& Glendinning, C. (2005). Dependence, independence, or inter-dependence? Revisiting the concepts of "care" and "dependency." Ageing \& Society, 25, 602-621. doi:10.1017/S0144686X05003600

Flemish Government. (2015). Vlaams Ouderenbeleidsplan 2015-2020 [Flemish policy plan on ageing 2015-2020]. Retrieved from https://www.vlaanderen.be/en/nbwa-newsmessage-document/document/09013557801b11b5

Garneau, A. B., Bourbonnais, A., \& Pepin, J. (2018). Striving for culturally competent elder care. In T. Boll, D. Ferring, \& J. Valsiner (Eds.), Cultures of care in aging (pp. 373392). Charlotte, NC: Information Age Publishing.

Gibson, D. M. (1985). The dormouse syndrome: Restructuring the dependency of the elderly. Australian and New Zealand Journal of Sociology, 21(1), 44-63. doi:10.1177/144078338502100103

Greene, V. L. (1983). Substitution between formally and informally provided care for the impaired elderly in the community. Medical Care, 21, 609-619.

Gregory, A., Mackintosh, S., Kumar, S., \& Grech, C. (2017). Experiences of health care for older people who need support to live at home: A systematic review of the qualitative literature. Geriatric Nursing, 38, 315-324. doi:10.1016/j. gerinurse.2016.12.001

Grenier, A. (2007). Constructions of frailty in the English language, care practice and the lived experience. Ageing \& Society, 27, 425-445. doi:10.1017/S0144686X06005782

Hoefman, R. J., Meulenkamp, T. M., \& De Jong, J. D. (2017). Who is responsible for providing care? Investigating the role of care tasks and past experiences in a cross-sectional survey in the Netherlands. BMC Health Services Research, 17, Article 477. doi:10.1186/s12913-017-2435-5
Hsieh, H.-F., \& Shannon, S. (2005). Three approaches to qualitative content analysis. Qualitative Health Research, 15, 1277-1288. doi:10.1177/1049732305276687

Jacobs, M., Van Tilburg, T., Groenewegen, P., \& Broese van Groenou, M. (2016). Linkages between informal and formal care-givers in home-care networks of frail older adults. Ageing \& Society, 36, 1604-1624. doi:10.1017/ S0144686X15000598

Jacobs, M. T., Broese van Groenou, M. I., Aartsen, M. J., \& Deeg, D. J. H. (2018). Diversity in older adults' care networks: The added value of individual beliefs and social network proximity. The Journals of Gerontology, Series B: Psychological Sciences and Social Sciences, 73, 326-336. doi:10.1093/geronb/gbw012

José, J. D. S., Barros, R., Samitca, S., \& Teixeira, A. (2016). Older persons' experiences and perspectives of receiving social care: A systematic review of the qualitative literature. Health and Social Care in the Community, 24(1), 111. doi:10.1111/hsc. 12186

Kahn, R. L., \& Antonucci, T. C. (1980). Convoys over the life course: A life course approach. In P. B. Baltes \& O. Brim (Eds.), Life span development and behavior (pp. 253-286). New York: Academic Press.

Keating, N., Otfinowski, P., Wenger, C., Fast, J., \& Derksen, L. (2003). Understanding the caring capacity of informal networks of frail seniors: A case for care networks. Ageing \& Society, 23, 115-127. doi:10.1017/S0144686X02008954

Kemp, C. L., Ball, M. M., Morgan, J. C., Doyle, P. J., Burgess, E. O., Dillard, J. A., \& Perkins, M. M. (2017). Exposing the backstage: Critical reflections on a longitudinal qualitative study of residents' care networks in assisted living. Qualitative Health Research, 27, 1190-1202. doi:10.1177/1049732316668817

Kemp, C. L., Ball, M. M., Morgan, J. C., Doyle, P. J., Burgess, E. O., . . . Perkins, M. M. (2018). Maneuvering together, apart, and at odds: Residents' care convoys in assisted living. Journals of Gerontology: Social Sciences, 73(4), e13e23. doi:10.1093/geronb/gbx184

Kemp, C. L., Ball, M. M., \& Perkins, M. M. (2013). Convoys of care: Theorizing intersections between formal and informal care. Journal of Aging Studies, 27(1), 15-29. doi:10.1016/j. jaging.2012.10.002

Kruijswijk, W., Da Roit, B., \& Hoogenboom, M. (2015). Elasticity of care networks and the gendered division of care. Ageing \& Society, 35, 675-703. doi:10.1017/ S0144686X13000822

Lambotte, D., De Donder, L., Van Regenmortel, S., Fret, B., Dury, S., Smetcoren, A.-S., . . K Kardol, M. J. M. (2018). Frailty differences in older adults' use of informal and formal care. Archives of Gerontology and Geriatrics, 79, 69-77. doi:10.1016/j.archger.2018.05.018

Lette, M., Baan, C. A., van den Berg, M., \& de Bruin, S. R. (2015). Initiatives on early detection and intervention to proactively identify health and social problems in older people: Experiences from the Netherlands. BMC Geriatrics, 15, Article 143. doi:10.1186/s12877-015-0131-z

Lewinter, M. (2003). Reciprocities in caregiving relationships in Danish elder care. Journal of Ageing Studies, 17, 357377. doi:10.1016/S0890-4065(03)00025-2 
Litwak, E. (1985). Perspectives on Marriage and the Family. Helping the elderly: The complementary roles of informal networks and formal systems. New York: Guilford Press.

Lloyd, A., Kendall, M., Starr, J. M., \& Murray, S. A. (2016). Physical, social, psychological and existential trajectories of loss and adaptation towards the end of life for older people living with frailty: A serial interview study. $B M C$ Geriatrics, 16, Article 176. doi:10.1186/s12877-0160350-y

Lommi, M., Matarese, M., Alvaro, R., Piredda, M., \& De Marinis, M. G. (2015). The experiences of self-care in community-dwelling older people: A meta-synthesis. International Journal of Nursing Studies, 52, 1854-1867. doi:10.1016/j.ijnurstu.2015.06.012

Means, R., Richards, S., \& Smith, R. (2008). Community care: Policy and practice (4th ed.). New York: Palgrave Macmillan.

Mello, J. D. A., Van Durme, J. M. T., Cès, S., Spruytte, N., Van Audenhove, C., \& Declercq, A. (2017). The determinants of informal caregivers' burden in the care of frail older persons: A dynamic and role-related perspective. Aging \& Mental Health, 21, 838-843. doi:10.1080/13607863.2016. 1168360

Metzelthin, S. F., Zijlstra, G. A. R., van Rossum, E., de Manvan Ginkel, J. M., Resnick, B., Lewin, G., . . Kempen, G. I. J. M. (2017). "Doing with . . " rather than "doing for ..." older adults: Rationale and content of the "Stay Active at Home" programme. Clinical Rehabilitation, 31, 1419-1430. doi:10.1177/0269215517698733

Moos, R. H. (1979). Social ecological perspectives on health. In G. C. Stone, F. Coeh, \& N. E. Adler (Eds.), Health psychology: A handbook (pp. 523-547). San Francisco: Jossey-Bass.

Morrow-Howell, N., Proctor, E. K., \& Dore, P. (1998). Adequacy of care: The concept and its measurement. Research on Social Work Practice, 8, 86-102. doi:10.1177 /104973159800800107

Nasreddine, Z. S., Phillips, N. A., Bedirian, V., Charbonneau, S., Whitehead, V., Collin, I., . . Chertkow, H. (2005). The Montreal Cognitive Assessment, MoCA: A brief screening tool for mild cognitive impairment. Journal of the American Geriatrics Society, 53, 695-699. doi:10.1111/ j.1532-5415.2005.53221.x

Nicholson, C., Gordon, A. L., \& Tinker, A. (2017). Changing the way "we" view and talk about frailty . . . Age and Ageing, 46, 349-351. doi:10.1093/ageing/afw224

Nicholson, C., Meyer, J., Flatley, M., \& Holman, C. (2013). The experience of living at home with frailty in old age: A psychosocial qualitative study. International Journal of Nursing Studies, 50, 1172-1179. doi:10.1016/j. ijnurstu.2012.01.006

Noble, H., \& Smith, J. (2015). Issues of validity and reliability in qualitative research. Evidence-Based Nursing, 18(2), 34-35. doi:10.1136/eb-2015-102054

Oliveira, M., Bitencourt, C., Teixeira, E., \& Santos, A. C. (2013). Thematic content analysis: Is there a difference between the support provided by the MAXQDA ${ }^{\circledR}$ and NVivo $^{\circledR}$ software packages. In A. Mesquita \& I. Ramos (Eds.), Proceedings of the 12th European Conference on Research Methodology for Business and Management Studies (pp. 304-314). Reading, UK: Academic Conferences and Publishing International Limited.

RIS MRC CFAS, Blamford, C., Gregson, B., Farrow, G., Buck, D., Dowswell, T., ... Wright, K. (1998). Mental and physical frailty in older people: The costs and benefits of informal care. Ageing \& Society, 18, 317-354.

Rockwood, K., Fox, R., Stolee, P., Robertson, D., \& Beattie, B. (1994). Frailty in elderly people: An evolving concept. Canadian Medical Association Journal, 150, 489495.

Smetcoren, A.-S. (2015). "I'm not leaving!?" Critical perspectives on "ageing in place" (Doctoral thesis). Vrije Universiteit Brussel, Belgium.

Stones, D., \& Gullifer, J. (2016). "At home it's just so much easier to be yourself": Older adults' perceptions of ageing in place. Ageing \& Society, 36, 449-481. doi:10.1017/ S0144686X14001214

Tronto, J. (1993). Moral boundaries: A political argument for an ethic of care. New York: Routledge.

Turcotte, P.-L., Larivière, N., Desrosiers, J., Voyer, P., Champoux, N., Carbonneau, H., . . Levasseur, M. (2015). Participation needs of older adults having disabilities and receiving home care: Met needs mainly concern daily activities, while unmet needs mostly involve social activities. BMC Geriatrics, 15, Article 95. doi:10.1186/s12877015-0077-1

van der Vorst, A., Zijlstra, G. A. R., De Witte, N., Vogel, R. G. M., Schols, J. M. G. A., Kempen, G. I. J. M., \& D-SCOPE Consortium. (2017). Explaining discrepancies in selfreported quality of life in frail older people: A mixed-methods study. BMC Geriatrics, 17, Article 251. doi:10.1186/ s12877-017-0641-y

Vandeurzen, J. (2016). Nabije zorg in een warm Vlaanderen. Vlaams Mantelzorgplan 2016-2020 [Proximity care in a hearty Flanders. Flemish informal care plan 2016-2020]. Retrieved from https://www.vlaanderen.be/nl/publicaties/ detail/nabij-zorg-in-een-warm-vlaanderen-vlaams-mantelzorgplan-2016-2020

Verver, D., Merten, H., Robben, P., \& Wagner, C. (2018). Care and support for older adults in the Netherlands living independently. Health and Social Care in the Community, 26, e404-e414. doi:10.1111/hsc.12539

Waibel, S., Vargas, I., Coderch, J., \& Vàzquez, M.-L. (2018). Relational continuity with primary and secondary care doctors: A qualitative study of perceptions of users of the Catalan national health system. Health Services Research, 18, 257. doi:10.1186/s12913-018-3042-9

Walsh, K., \& Shutes, I. (2013). Care relationships, quality of care and migrant workers caring for older people. Ageing \& Society, 33, 393-420. doi:10.1017/ S0144686X11001309

Ward-Griffin, C., \& Marshall, V. W. (2003). Reconceptualizing the relationship between "public" and "private" eldercare. Journal of Aging Studies, 17, 189-208. doi:10.1016/S08904065(03)00004-5 
Warmoth, K., Lang, I. A., Phoenix, C., Abraham, C., Andrew, M. K., Hubbard, R. E., \& Tarrant, M. (2016). "Thinking you're old and frail": A qualitative study of frailty in older adults. Ageing \& Society, 36, 1483-1500. doi:10.1017/ S0144686X1500046X

Wiles, J. (2011). Reflections on being a recipient of care: Vexing the concept of vulnerability. Social \& Cultural Geography, 12, 573-588. doi:10.1080/14649365.2011.601237

Witham, G., Haigh, C., Mitchell, D., \& Beddow, A. (2018). Carer experience supporting someone with dementia and cancer: A narrative approach. Qualitative Health Research, 28, 813-823. doi:10.1177/1049732317736285

\section{Author Biographies}

Deborah Lambotte wrote a $\mathrm{PhD}$ on the dynamics of care networks of frail, community-dwelling older adults at the Department of Educational Sciences, Vrije Universiteit Brussel.
The $\mathrm{PhD}$ is part of the $\mathrm{D}$-SCOPE project. She currently works as a Lecturer at the College University Ghent.

An-Sofie Smetcoren currently works as a postdoctoral researcher at the Department of Educational Sciences, Vrije Universiteit Brussel.

G. A. Rixt Zijlstra is assistant professor at the CAPHRI Care and Public Health Research Institute, Maastricht University.

Jan De Lepeleire is professor at the Faculty of Medicine, University of Leuven.

Liesbeth De Donder is professor at the Department of Adult Educational Sciences, Vrije Universiteit Brussel.

Martinus J. M. Kardol is holder of the academic chair Active Ageing, Vrije Universiteit Brussel.

D-SCOPE Consortium's details is given in the Acknowledgments section. 